\title{
The Potential for Healthy Checkout Policies to Advance Nutri- tion Equity
}

\author{
Jennifer Falbe ${ }^{1, *}$, Justin S. White ${ }^{2}$, Desiree M. Sigala ${ }^{3}$, Anna H. Grummon ${ }^{4}$, Sarah E. Solar ${ }^{5}$, and Lisa M. Powell ${ }^{6}$
}

1 Human Development Program, Department of Human Ecology, University of California, Davis; jfalbe@ucdavis.edu

2 Philip R. Lee Institute for Health Policy Studies, University of California, San Francisco; Justin.White@ucsf.edu

3 Department of Molecular Biosciences, School of Veterinary Medicine, University of California, Davis, CA; dmsigala@ucdavis.edu

4 Department of Nutrition, Harvard TH Chan School of Public Health; agrummon@hsph.harvard.edu

5 Department of Human Ecology, University of California, Davis; sesolar@ucdavis.edu

6 Division of Health Policy and Administration, School of Public Health, University of Illinois Chicago; powelll@uic.edu

* Correspondence: jfalbe@ucdavis.edu

\begin{abstract}
Background: As the only place in a store where all customers must pass through and wait, the checkout lane may be particularly influential over consumer purchases. Because most foods and beverages sold at checkout are unhealthy (e.g., candy/sweets, sugar-sweetened beverages, and salty snacks), policymakers and advocates have expressed growing interest in healthy checkout policies. To understand the extent to which such policies could improve nutrition equity, we assessed the prevalence and sociodemographic correlates of purchasing items from checkout. Methods: We assessed self-reported checkout purchasing and sociodemographic characteristics in a national convenience sample of adults $(n=10,348)$ completing an online survey in 2021. Results: Over one-third (36\%) of participants reported purchasing foods or drinks from checkout during their last grocery shopping trip. Purchasing items from checkout was more common among men; adults $<55$ years of age; low-income consumers; Hispanic, non-Hispanic American Indian and Alaska Native, and nonHispanic Black consumers; those with at least a bachelor's degree; parents; and consumers diagnosed with type 2 diabetes or pre-diabetes ( $p$-values<0.05). Conclusions: Purchasing foods or beverages from store checkouts is common and more prevalent among low-income and racial and ethnic minority groups. These results suggest that healthy checkout policies have the potential to improve nutrition equity.
\end{abstract}

Keywords: checkout, policy, product placement, obesity, nutrition, retail, marketing, disparities, race, income.

\section{Introduction}

Two-thirds of calories in the US diet come from grocery stores,[1,2] making the retail food environment a key opportunity for improving diet quality. Multiple reviews have found that characteristics of store food environments influence consumer purchases, especially product placement and pricing.[3-5] The store food environment may also affect health outcomes. For example, higher exposure to store displays for sugar-sweetened beverages and foods high in added sugars has been associated with higher customer body mass index.[6]

Checkout lanes represent a particularly promising target for intervention. Checkout lanes are the only place in the store where all customers must pass through and wait. Moreover, checkout lanes are known for high levels of impulse purchases.[7,8] Thus, processed food 
manufacturers pay stores large sums of money to place their products at checkout.[9] Indeed, the most common foods and beverages found at checkout include candy, sugarsweetened beverages, salty snacks, and sweets.[10-13] The food environment in checkout lanes also might contribute to prevailing inequities in dietary and health outcomes, such as higher consumption of unhealthy foods and beverages and higher prevalence of obesity in low-income, Black, and Hispanic populations.[14-19] One national study, for example, found that stores in low-income communities were less likely to carry fresh fruits and vegetables at checkout than stores in higher income communities.[10]

Some stores in the US have made voluntary changes to improve the healthfulness of their checkouts. These changes have typically been short-term, narrow in scope (e.g., converting only one checkout lane per store), and not widely adopted. To address this issue, in 2021 Berkeley, California became the first jurisdiction in the US, and to our knowledge the first in the world, to implement a healthy checkout policy.[20,21] The ordinance prohibits sweetened beverages and foods containing $>5 \mathrm{~g}$ of added sugars or $>200 \mathrm{mg}$ of sodium per serving from being displayed at checkout. The UK recently followed suit, adopting a healthy checkout policy that will be implemented in 2022.[22,23] These policies have the potential to encourage healthier purchases. Assessments of voluntary standards in the UK restricting junk food at checkouts found that the standards were associated with fewer purchases of small packages of sweets and salty snacks commonly sold at checkout.[24]

The extent to which healthy checkout policies improve consumer purchases, and ultimately dietary intake and chronic disease risk, depends in part on how frequently consumers purchase foods and beverages from checkout. Further, the extent to which checkout policies may advance nutrition equity depends upon which segments of the population are more likely to make purchases from checkout. To date, limited published research has examined checkout behaviors. Therefore, the objective of this study was to assess the prevalence and frequency of purchasing from checkout and to identify sociodemographic correlates of this practice.

\section{Materials and Methods}

\subsection{Participants Design}

This study draws data from a national online sample of 15,502 US adults recruited in May-June 2021 to match the 2018 American Community Survey (ACS) 5-year estimates[25] for age (18-34, 35-54, $\geq 55$ years), gender, race/ethnicity (Hispanic [any race], non-Hispanic (NH) White, NH Black, and NH Asian) and education (high school degree or equivalent, some college, at least a bachelor's degree). The sample was recruited by Dynata, which maintains panels of US adults recruited using open enrollment and byinvitation-only methods.[26]

\subsection{Procedures}

Participants provided informed consent and completed a screener to assess eligibility. Eligible participants were English-speaking US residents aged 18-99 years who reported purchasing items from restaurants $\geq 1$ time per month prior to the pandemic and passed a Captcha. Participants then completed a 10-15 min Qualtrics survey. The primary purpose of the survey was to test the effect of warning labels for restaurant menu items high in added sugars in a hypothetical menu ordering task (manuscript under review). After completing this ordering task, participants answered questions about purchasing items from grocery store checkouts, as described below. This study was approved by the UC Davis Institutional Review Board.

\subsection{Measures}


Two novel questions assessed purchasing from checkout: (1) "The last time you went to the grocery store, did you purchase any foods or drinks that you found in the checkout area? (yes or no)" and (2) "Before the pandemic, how often did you purchase something you found in the checkout area of a store? ( 3 or more times per week, 2 times per week, 1 time per week, 2-3 times per month, 1 time per month, or less than 1 time per month)."

The questionnaire assessed the following sociodemographic characteristics: gender, continuous age, race and ethnicity (Hispanic, American Indian or Alaska Native, Asian, Black, Native Hawaiian or other Pacific Islander, Middle Easter or north African, or White), educational attainment, total household income in the last 12 months before taxes $(<\$ 20,001, \$ 20,001$ to $\$ 150,000$ in $\$ 15,000$ increments, and $>\$ 150,000)$, being a parent or caregiver of a child age 0-17 years, and having been diagnosed with pre-diabetes or type 2 diabetes. An attention check question asked participants to select the current month. If a participant selected the incorrect month, they were classified as having failed the attention check question.

For the analysis, age was categorized into 18-34, 35-54, and 55+ years and educational attainment into up to a high school degree, some college, and bachelor's degree or higher. Race and ethnicity were grouped as Hispanic any race and NH American Indian or Alaska Native, NH Asian, NH Black, NH multi-race, NH Native Hawaiian or other Pacific islander, and NH White. Income was categorized into quartiles, and diagnosis with either pre-diabetes or type 2 diabetes were combined into a single dichotomous variable.

\subsection{Analytic Sample}

Because items assessing checkout behaviors were added after the survey's launch, a total of 10,774 participants took a version of the questionnaire with checkout questions. Of the 10,774 participants, we excluded 381 for failing the attention check question and 45 for completing the survey in less than $30 \%$ of the median completion time, leaving an analytic sample of 10,348 .

\subsection{Statistical Analysis}

Counts and percentages were used to present descriptive statistics regarding sociodemographic characteristics and checkout purchasing behaviors. Prior to conducting main analyses, we assessed whether random exposure to the restaurant warning label in the menu ordering task affected participant responses to the checkout questions using a Poisson regression models with a robust error variance[27] for the question assessing probability of purchasing from checkout during the last shopping trip and a chi-square test for the question assessing categorical frequency of checkout purchases. Results revealed no significant association between experimental condition in the menu ordering task and checkout purchasing behaviors ( $p$-values $>0.05$ ).

To examine the association between sociodemographic characteristics and probability of purchasing foods and drinks from checkout during the last shopping trip, we calculated prevalence ratios using Poisson regression models with a robust error variance.[27] The first model examined unadjusted bivariate associations between each characteristic and purchasing foods or drinks from checkout. The second model (i.e., the adjusted model) included all sociodemographic variables in the same model. Analyses used complete case analysis and were conducted using Stata/MP v15.1 in 2021 (StataCorp LLC, College Station, TX).

\section{Results}

\subsection{Sample characteristics}

The sample was $56 \%$ women, $19 \%$ Hispanic of any race, $16 \%$ NH Black, $6 \% \mathrm{NH}$ Asian, and $57 \%$ NH White (Table 1). Nearly $40 \%$ had no more than a high school degree 
or GED, 38\% had some college or associate's degree, and $22 \%$ had at least a bachelor's degree.

Table 1. Sociodemographic characteristics of a national sample of US adults

\begin{tabular}{|c|c|}
\hline Characteristic & n $(\%)$ \\
\hline $\mathrm{N}$ & 10,348 \\
\hline \multicolumn{2}{|l|}{ Gender } \\
\hline Man & $4,528(44 \%)$ \\
\hline Non-binary / gender nonconforming & $46(<1 \%)$ \\
\hline Woman & $5,774(56 \%)$ \\
\hline \multicolumn{2}{|l|}{ Age } \\
\hline 18-34 years & $2,644(26 \%)$ \\
\hline $35-54$ years & $3,053(30 \%)$ \\
\hline $55+$ years & $4,651(45 \%)$ \\
\hline \multicolumn{2}{|l|}{ Race/ethnicity } \\
\hline Hispanic, any race & $2,012(19 \%)$ \\
\hline NH American Indian or Alaska Native & $56(1 \%)$ \\
\hline NH Asian & $667(6 \%)$ \\
\hline NH Black & $1,605(16 \%)$ \\
\hline NH multi-race & $94(1 \%)$ \\
\hline NH Native Hawaiian / other Pacific islander & $13(<1 \%)$ \\
\hline NH White & $5,901(57 \%)$ \\
\hline \multicolumn{2}{|l|}{ Education level } \\
\hline Less than high school or GED & $339(3 \%)$ \\
\hline High school or GED & $3,781(37 \%)$ \\
\hline Some college or associate's degree & $3.950(38 \%)$ \\
\hline Bachelor's degree & $1,396(13 \%)$ \\
\hline Graduate or professional degree & $882(9 \%)$ \\
\hline \multicolumn{2}{|l|}{ Annual household income before taxes } \\
\hline$\leq \$ 35,000$ & $3,163(31 \%)$ \\
\hline$\$ 35,001-65,000$ & $2,911(28 \%)$ \\
\hline$\$ 65,001-95,000$ & $1,838(18 \%)$ \\
\hline$>\$ 95,000$ & $2,385(23 \%)$ \\
\hline Parent or caregiver of child $<18$ years & $2,680(26 \%)$ \\
\hline Diagnosed with pre-diabetes or type 2 diabetes & $2,233(22 \%)$ \\
\hline \multicolumn{2}{|l|}{ Region } \\
\hline West & $2,226(22 \%)$ \\
\hline Midwest & $1,979(19 \%)$ \\
\hline Northeast & $2,037(20 \%)$ \\
\hline South & $4,087(40 \%)$ \\
\hline US Territory & $13(<1 \%)$ \\
\hline
\end{tabular}

Note: Missing responses were not included in the denominator for calculating percentages. Data were missing for only income, parent or caregiver status, diabetes diagnosis, and region and ranged from $0.1-3 \%$ of observations.

GED-general education development; $\mathrm{NH}-$ non-Hispanic

\subsection{Purchasing from checkout}

More than one-third (36\%) of participants reported purchasing foods or drinks found in the checkout area during their last grocery store trip (Table 2). Additionally, $51 \%$ reported that before the pandemic, they purchased something found at checkout at least once per month, with $29 \%$ reporting doing so at least once per week (Table 2 ). 
Table 2. Proportion of participants purchasing items from checkout and frequency of this practice in a national sample of US adults

\begin{tabular}{|c|c|}
\hline Questionnaire item & n $(\%)$ \\
\hline \multicolumn{2}{|c|}{$\begin{array}{l}\text { "The last time you went to the grocery store, did you purchase any } \\
\text { foods or drinks that you found in the checkout area?" }(n=10,343)\end{array}$} \\
\hline Yes & $3,688(36 \%)$ \\
\hline No & $6,655(64 \%)$ \\
\hline \multicolumn{2}{|c|}{$\begin{array}{l}\text { "Before the pandemic, how often did you purchase something you } \\
\text { found in the checkout area of a store?" }(n=10,337)\end{array}$} \\
\hline Less than 1 time per month & $5,037(49 \%)$ \\
\hline 1 time per month & $1,035(10 \%)$ \\
\hline 2-3 times per month & $1,251(12 \%)$ \\
\hline 1 time per week & $1,242(12 \%)$ \\
\hline 2 times per week & $1,000(10 \%)$ \\
\hline 3 or more times per week & $772(7 \%)$ \\
\hline
\end{tabular}

\subsection{Sociodemographic characteristics associated with purchasing items from checkout}

Table 3 presents unadjusted and adjusted associations between sociodemographic characteristics and purchasing foods or drinks from checkout during the last grocery shopping trip. In unadjusted and adjusted models, men were more likely than women, and younger adults (age 18-54) were more likely than older adults, to report purchasing foods or drinks from checkout. Adjusted estimates for race and ethnicity were substantially attenuated compared to estimates in the unadjusted models, but the adjusted probability of purchasing from checkout remained significantly higher than NH White participants for Hispanic (1.1 times higher), NH American Indian and Alaska Native (1.4 times higher), and NH Black participants (1.3 times higher). In unadjusted and adjusted models, having a low household income, being a parent, and having had a diagnosis of type 2 diabetes or pre-diabetes were associated with a higher probability of purchasing from checkout. In contrast, those with lower educational attainment were less likely to purchase from checkout than those with at least a bachelor's degree.

Table 3. Prevalence and prevalence ratios of purchasing foods or drinks found in the checkout area during the last grocery shopping trip by sociodemographic characteristics

\begin{tabular}{|c|c|c|c|}
\hline & \multirow{2}{*}{$\begin{array}{l}\text { Prevalence of purchas- } \\
\text { ing from checkout } \\
\text { n ( } \%)\end{array}$} & \multicolumn{2}{|c|}{$\begin{array}{l}\text { Prevalence ratio }(95 \% \mathrm{CI})^{1} \text { of purchasing } \\
\text { from checkout }\end{array}$} \\
\hline & & $\begin{array}{c}\text { Unadjusted } \\
\text { bivariate }(n \geq 10,277)^{2}\end{array}$ & Adjusted $^{3}(n=10,214)$ \\
\hline \multicolumn{4}{|l|}{ Gender } \\
\hline Man & $1,817(40 \%)$ & $1.25(1.19,1.32)^{* * *}$ & $1.12(1.07,1.18)^{* * *}$ \\
\hline Gender non-conforming & $17(37 \%)$ & $1.15(0.79,1.68)$ & $0.76(0.51,1.14)$ \\
\hline Woman & $1,854(32 \%)$ & ref & ref \\
\hline \multicolumn{4}{|l|}{ Age } \\
\hline $18-34$ & $1,700(64 \%)$ & $5.76(5.28,6.27)^{* * *}$ & $4.46(4.04,4.93)^{* * *}$ \\
\hline $35-54$ & $1,468(48 \%)$ & $4.30(3.93,4.70)^{* * *}$ & $3.26(2.96,3.60)^{* * *}$ \\
\hline $55+$ & $520(11 \%)$ & ref & ref \\
\hline \multicolumn{4}{|l|}{ Race and ethnicity } \\
\hline Hispanic, any race & $1,015(51 \%)$ & $2.10(1.97,2.23)^{* * *}$ & $1.12(1.05,1.19)^{* * *}$ \\
\hline NH American Indian or Alaska Native & $42(75 \%)$ & $3.11(2.66,3.65)^{* * *}$ & $1.37(1.19,1.59)^{* * *}$ \\
\hline
\end{tabular}




\section{Prevalence of purchas- Prevalence ratio $(95 \% \mathrm{CI})^{1}$ of purchasing ing from checkout from checkout}

\begin{tabular}{|c|c|c|c|}
\hline & n (\%) & $\begin{array}{c}\text { Unadjusted } \\
\text { bivariate }(\mathrm{n} \geq 10,277)^{2} \\
\end{array}$ & Adjusted $^{3}(n=10,214)$ \\
\hline NH Asian & $212(32 \%)$ & $1.32(1.17,1.49)^{* * *}$ & $0.90(0.81,1.01)^{\mathrm{c}}$ \\
\hline NH Black & $946(59 \%)$ & $2.45(2.30,2.60)^{* * *}$ & $1.25(1.18,1.33)^{* * *}$ \\
\hline NH multi-race & $45(48 \%)$ & $1.99(1.60,2.47)^{* * *}$ & $1.20(0.98,1.47)^{c}$ \\
\hline $\begin{array}{l}\text { NH Native Hawaiian or other Pacific is- } \\
\text { lander }\end{array}$ & $7(54 \%)$ & $2.24(1.35,3.71)^{* *}$ & $1.09(0.64,1.86)$ \\
\hline NH White & $1,421(24 \%)$ & ref & ref \\
\hline \multicolumn{4}{|l|}{ Educational attainment } \\
\hline Up to high school degree or GED & $1,469(36 \%)$ & $0.79(0.74,0.84)^{* * *}$ & $0.91(0.85,0.97)^{* *}$ \\
\hline Some college or associate's degree & $1,186(30 \%)$ & $0.66(0.62,0.71)^{* * *}$ & $0.87(0.82,0.93)^{* * *}$ \\
\hline Bachelor's degree or higher & $1,033(45 \%)$ & ref & ref \\
\hline \multicolumn{4}{|l|}{ Annual household income before taxes } \\
\hline$\leq \$ 35,000$ & $1,310(41 \%)$ & $1.10(1.03,1.17)^{* *}$ & $1.24(1.15,1.32)^{* * *}$ \\
\hline$\$ 35,001-\$ 65,000$ & $885(30 \%)$ & $0.80(0.75,0.87)^{* * *}$ & $1.07(1.00,1.15)^{\mathrm{c}}$ \\
\hline$\$ 65,001-\$ 95,000$ & $580(32 \%)$ & $0.83(0.77,0.91)^{* * *}$ & $1.06(0.98,1.14)$ \\
\hline$>\$ 95,000$ & $902(38 \%)$ & ref & ref \\
\hline \multicolumn{4}{|l|}{ Parent or caregiver of child $<18$ years of age } \\
\hline Parent of a child & $1,710(64 \%)$ & $2.48(2.36,2.60)^{* * *}$ & $1.50(1.42,1.57)^{* * *}$ \\
\hline Not a parent of a child & $1,958(26 \%)$ & ref & ref \\
\hline \multicolumn{4}{|l|}{ Type 2 diabetes or pre-diabetes diagnosis } \\
\hline Diagnosis & $842(38 \%)$ & $1.08(1.01,1.14)^{*}$ & $1.26(1.19,1.33)^{* * *}$ \\
\hline No diagnosis & $2,820(35 \%)$ & ref & ref \\
\hline
\end{tabular}

Note: The outcome was assessed with the question, "The last time you went to the grocery store, did you purchase any foods or drinks that you found in the checkout area?" (yes/no).

${ }^{1}$ Prevalence ratios, 95\% CI, and $p$-values were calculated from Poisson regression models with robust standard errors.

${ }^{2}$ The sample size for models in which independent variables were gender, age, race/ethnicity, and education was 10,343. Sample sizes for models in which the independent variables were income, parent/caregiver, and diagnosis with type 2 diabetes/pre-diabetes were 10,292,10,282, and 10,277, respectively.

${ }^{3}$ The adjusted model included all characteristics in Table 3 as independent variables.

${ }^{* * *} \mathrm{P}<0.001,{ }^{* *} \mathrm{P}<0.01, c \mathrm{P}<0.10$

$\mathrm{CI}-$ confidence interval; $\mathrm{NH}-$ non-Hispanic.

\section{Discussion}

In this large, national sample of US adults, more than one in three (36\%) participants reported purchasing foods or drinks from checkout during their last grocery shopping trip. Further, most participants (51\%) reported purchasing something from checkout at least monthly prior to the pandemic. Consistent with the hypothesis that stocking checkout with poor quality foods and beverages may contribute to inequities, we found that the lowest income participants were more likely to purchase foods and drinks from checkout than the highest income participants, as were Hispanic, NH American Indian or Alaska native, and NH Black participants compared to NH White participants. Further, parents, men, adults under age 55, and those reporting a diagnosis of type 2 diabetes or pre-diabetes were more likely to report purchasing foods or drinks from checkout. Those with less than a bachelor's degree were less likely to purchase from checkout. This is the first study to our knowledge to use a national US sample to examine the prevalence and frequency of purchasing items from checkout and to identify groups among which checkout purchases were more common. This information is key for understanding the extent to which healthy checkout policies can improve diet quality and reduce nutrition and health inequities. 
We are unaware of any other studies in the US to examine reported purchasing of foods or beverages from checkout. However, one study in which researchers observed behaviors during specific times at three South Bronx supermarkets in New York City found that only $4 \%$ of customers purchased an item from checkout.[28] The authors noted though that the checkouts in these stores were compact, moved quickly, and were not representative of checkouts more broadly. In contrast to our results, a study in the UK that analyzed household purchases from nine leading supermarkets found no association between socioeconomic status and number of purchases of foods commonly sold at checkout.[29] However, that study was unable to determine whether foods commonly sold at checkout were actually obtained at checkout or elsewhere in the store.

In our sample, a sizable proportion of the population reported purchasing foods or beverages from checkout, and this practice was more common among low-income and racial and ethnic minority consumers. These results suggest that healthy checkout policies have the potential to improve diet quality and promote nutrition equity. Although there are no evaluations of mandatory checkout policies like the ones recently adopted in Berkeley and the UK, studies of voluntary initiatives indicate that healthy checkout policies may improve the nutritional quality of store purchases. The strongest evidence comes from a natural experiment in the UK, where, multiple chains implemented voluntary checkout standards. Using data from household purchases and comparing UK stores with checkout standards to those without, researchers found that checkout standards reduced sales of unhealthy checkout foods by $17 \%$.[24] Other evaluations of voluntary checkout initiatives have found that the initiatives increased purchases of healthier products or decreased purchases of unhealthy products.[28,30-35]

A strength of this study is the large and diverse national sample of participants. Limitations include that purchasing behaviors were self-reported, and the questionnaire did not assess types of foods or beverages purchased from checkout. Additionally, we did not recruit a probability sample, so results may not generalize to the US as a whole, although the sample was recruited to approximately match the US adult population with respect to categories of age, gender, race/ethnicity, and educational attainment.

\section{Conclusions}

Purchases from checkout are common and more prevalent among low-income and racial and ethnic minority consumers. Together with prior research documenting the poor quality of foods and beverages displayed at checkout, these findings indicate that healthy checkout policies hold promise for improving nutrition and health equity. Additionally, this study's findings that parents and those diagnosed with diabetes or pre-diabetes were more likely to purchase foods and drinks from checkout suggest that checkout policies may have broad reach to adults and children and those most at risk for nutrition-related health harms. Such policies should be rigorously evaluated to determine their impacts on consumer behavior and nutrition equity.

Author Contributions: Conceptualization, J.F.; methodology, J.F.,; formal analysis, J.F.; data curation, J.F., S.E.S.; data interpretation, J.S.W., A.H.G., S.E.S., L.M.P., writing-original draft preparation, J.F.; writing - review and editing, J.S.W., A.H.G., S.E.S., L.M.P.; funding acquisition, J.F. All authors have read and agreed to the published version of the manuscript.

Funding: The survey that generated data for this research was funded by the Center for Science in the Public Interest (CSPI). Dr. Falbe is supported by NIH/NIDDK K01DK113068 and USDA/NIFA Hatch project 1016627. Dr. Sigala is supported by the NIH/NHLBI Postdoctoral Diversity Supplement R01HL137716. Dr. Grummon is supported by NIH/NHLBI T32HL098048. Dr. Powell is supported by Bloomberg Philanthropies Food Policy Program (grant number 2020-85774). The content is solely the responsibility of the authors and does not necessarily represent the official views or policy of CSPI, the NIH, the USDA, or Bloomberg Philanthropies. 
Institutional Review Board Statement: The study was conducted according to the guidelines of the Declaration of Helsinki, and approved as exempt by the Institutional Review Board of UC Davis (protocol number 1641776-4).

Informed Consent Statement: Informed consent was obtained from all subjects involved in the study.

Data Availability Statement: The data presented in this study are available on request from the corresponding author. The data are not publicly available to protect participant privacy.

Conflicts of Interest: The authors declare no conflict of interest. Although CSPI played a role in the design and writing of the warning label study described in this paper, the funders, including CSPI, had no role in the design or conduct of this secondary analysis of checkout purchase behaviors or interpretation of data; in the decision to add questions about checkout behaviors or the wording of the items about checkout behaviors; in the writing of the manuscript, or in the decision to publish the results must be declared in this section.

\section{References}

1. Drewnowski, A.; Rehm, C.D. Consumption of added sugars among US children and adults by food purchase location and food source. Am J Clin Nutr 2014, 100, 901-907, doi:10.3945/ajcn.114.089458.

2. Liu, J.; Micha, R.; Li, Y.; Mozaffarian, D. Trends in Food Sources and Diet Quality Among US Children and Adults, 20032018. JAMA Netw Open 2021, 4, e215262, doi:10.1001/jamanetworkopen.2021.5262.

3. Hecht, A.A.; Perez, C.L.; Polascek, M.; Thorndike, A.N.; Franckle, R.L.; Moran, A.J. Influence of Food and Beverage Companies on Retailer Marketing Strategies and Consumer Behavior. Int J Environ Res Public Health 2020, 17, doi:10.3390/ijerph17207381.

4. Bennett, R.; Zorbas, C.; Huse, O.; Peeters, A.; Cameron, A.J.; Sacks, G.; Backholer, K. Prevalence of healthy and unhealthy food and beverage price promotions and their potential influence on shopper purchasing behaviour: A systematic review of the literature. Obes Rev 2020, 21, e12948, doi:10.1111/obr.12948.

5. Glanz, K.; Bader, M.D.; Iyer, S. Retail grocery store marketing strategies and obesity: an integrative review. Am J Prev Med 2012, 42, 503-512, doi:10.1016/j.amepre.2012.01.013.

6. Cohen, D.A.; Collins, R.; Hunter, G.; Ghosh-Dastidar, B.; Dubowitz, T. Store Impulse Marketing Strategies and Body Mass Index. Am J Public Health 2015, 105, 1446-1452, doi:10.2105/ajph.2014.302220.

7. Cohen, D.A.; Babey, S.H. Candy at the cash register--a risk factor for obesity and chronic disease. N Engl J Med 2012, 367, 1381-1383, doi:10.1056/NEJMp1209443.

8. Cohen, D.A.; Babey, S.H. Contextual influences on eating behaviours: heuristic processing and dietary choices. Obes Rev 2012, 13, 766-779, doi:10.1111/j.1467-789X.2012.01001.x.

9. Center for Science in the Public Interest (CSPI); Rivlin, G. Rigged: Supermarket Shelves for Sale. Availabe online: https://cspinet.org/resource/rigged (accessed on January 27).

10. Barker, D.; Quinn, C.; Rimkus, L.; Mineart, C.; Zenk, S.; Chaloupka, F. Availability of Healthy Food Products at Check-Out Nationwide, 2010-2012. A BTG Research Brief. Bridging the Gap Program, Health Policy Center, Institute for Health Research and Policy, University of Illinois at Chicago, Chicago, IL 2015.

11. Basch, C.H.; Fera, J. Candy, Snack Food, and Soda in the Checkout Lines of Stores Selling Products for Children in New York City. Journal of community health 2021, 10.1007/s10900-021-00975-4, 1-5, doi:10.1007/s10900-021-00975-4.

12. Basch, C.H.; Kernan, W.D.; Menafro, A. Presence of Candy and Snack Food at Checkout in Chain Stores: Results of a Pilot Study. Journal of community health 2016, 41, 1090-1093, doi:10.1007/s10900-016-0193-7.

13. Fielding-Singh, P.; Almy, J.; Wootan, M.C. Sugar overload: Retail checkout promotes obesity. Availabe online: https://cspinet.org/resource/sugar-overload-retail-checkout-promotes-obesity (accessed on April 4). 
14. Singleton, C.R.; Winkler, M.; Houghtaling, B.; Adeyemi, O.S.; Roehll, A.M.; Pionke, J.J.; Anderson Steeves, E. Understanding the Intersection of Race/Ethnicity, Socioeconomic Status, and Geographic Location: A Scoping Review of U.S. Consumer Food Purchasing. Int J Environ Res Public Health 2020, 17, doi:10.3390/ijerph17207677.

15. Roesler, A.; Rojas, N.; Falbe, J. Sugar-Sweetened Beverage Consumption, Perceptions, and Disparities in Children and Adolescents. J Nutr Educ Behav 2021, 53, 553-563, doi:10.1016/j.jneb.2021.04.004.

16. Falbe, J.; Cotterman, C.; Linchey, J.; Madsen, K.A. Ethnic Disparities in Trends in High BMI Among California Adolescents, 2003-2012. Am J Prev Med 2016, 10.1016/j.amepre.2016.02.010, doi:10.1016/j.amepre.2016.02.010.

17. Ogden, C.L.; Fakhouri, T.H.; Carroll, M.D.; Hales, C.M.; Fryar, C.D.; Li, X.; Freedman, D.S. Prevalence of Obesity Among Adults, by Household Income and Education - United States, 2011-2014. MMWR. Morbidity and mortality weekly report 2017, 66, 1369-1373, doi:10.15585/mmwr.mm6650a1.

18. Hales, C.; Carroll, M.; Fryar, C.; Ogden, C. Prevalence of obesity and severe obesity among adults: United States, 2017-2018. NCHS data brief 2020, 360 .

19. Bailey, Z.D.; Krieger, N.; Agenor, M.; Graves, J.; Linos, N.; Bassett, M.T. Structural racism and health inequities in the USA: evidence and interventions. Lancet 2017, 389, 1453-1463, doi:10.1016/s0140-6736(17)30569-x.

20. Ford, D. Berkeley Approves 'Healthy Checkout Ordinance' Banning Junk Food Sales By Grocery Registers. CBS SF BayArea September 23, 2020.

21. City of Berkeley. Ordinance NO. 7,734-N.S. Adding Chapter 9.82 to The Berkeley Municipal Code "Healthy Checkout". Availabe $\quad$ online: $\quad$ https://www.cityofberkeley.info/Clerk/City Council/2020/10 Oct/Documents/2020-1013_Item_02_Ordinance 7734.aspx (accessed on

22. Department of Health and Social Care. Promotions of unhealthy foods restricted from April 2022 Availabe online: https://www.gov.uk/government/news/promotions-of-unhealthy-foods-restricted-from-april-2022 (accessed on October 26).

23. Walker, P. Unhealthy snacks to be banned from checkouts at supermarkets in England. The Guardian December 27, 2020.

24. Ejlerskov, K.T.; Sharp, S.J.; Stead, M.; Adamson, A.J.; White, M.; Adams, J. Supermarket policies on less-healthy food at checkouts: Natural experimental evaluation using interrupted time series analyses of purchases. PLoS Med 2018, 15, e1002712, doi:10.1371/journal.pmed.1002712.

25. 2013-2018 American Community Survey Availabe online: https://www.census.gov/acs/www/data/data-tables-andtools/data-profiles/2018/ (accessed on May 8).

26. Dynata. Panel Quality: Our Values; Answers to ESOMAR's 28 Questions; 2018.

27. Zou, G. A modified poisson regression approach to prospective studies with binary data. Am J Epidemiol 2004, 159, 702-706.

28. Adjoian, T.; Dannefer, R.; Willingham, C.; Brathwaite, C.; Franklin, S. Healthy Checkout Lines: A Study in Urban Supermarkets. J Nutr Educ Behav 2017, 49, 615-622.e611, doi:10.1016/j.jneb.2017.02.004.

29. Ejlerskov, K.; Sharp, S.J.; Stead, M.; Adamson, A.J.; White, M.; Adams, J. Socio-economic and age variations in response to supermarket-led checkout food policies: a repeated measures analysis. Int J Behav Nutr Phys Act 2018, 15, 125, doi:10.1186/s12966-018-0755-4.

30. Foster, G.D.; Karpyn, A.; Wojtanowski, A.C.; Davis, E.; Weiss, S.; Brensinger, C.; Tierney, A.; Guo, W.; Brown, J.; Spross, C., et al. Placement and promotion strategies to increase sales of healthier products in supermarkets in low-income, ethnically diverse neighborhoods: a randomized controlled trial. Am J Clin Nutr 2014, 99, 1359-1368, doi:10.3945/ajcn.113.075572.

31. Huitink, M.; Poelman, M.P.; Seidell, J.C.; Pleus, M.; Hofkamp, T.; Kuin, C.; Dijkstra, S.C. Can unhealthy food purchases at checkout counters be discouraged by introducing healthier snacks? A real-life experiment in supermarkets in deprived urban areas in the Netherlands. BMC Public Health 2020, 20, 542, doi:10.1186/s12889-020-08608-6.

32. Payne, C.; Niculescu, M. Can healthy checkout end-caps improve targeted fruit and vegetable purchases? Evidence from grocery and SNAP participant purchases. Food Policy 2018, 79, 318-323, doi:https://doi.org/10.1016/j.foodpol.2018.03.002. 
33. Sigurdsson, V.; Larsen, N.M.; Gunnarsson, D. Healthy food products at the point of purchase: An in - store experimental analysis. Journal of applied behavior analysis 2014, 47, 151-154.

34. Van Gestel, L.C.; Kroese, F.M.; De Ridder, D.T.D. Nudging at the checkout counter - A longitudinal study of the effect of a food repositioning nudge on healthy food choice. Psychology $\mathcal{E}$ health 2018, 33, 800-809, doi:10.1080/08870446.2017.1416116.

35. van Kleef, E.; Otten, K.; van Trijp, H.C.M. Healthy snacks at the checkout counter: A lab and field study on the impact of shelf arrangement and assortment structure on consumer choices. BMC Public Health 2012, 12, 1072, doi:10.1186/1471-245812-1072. 